\title{
Lifestyle and oxidative stress status in infertile women in Dar es Salaam, Tanzania: comparative cross-sectional study
}

\author{
Anna Gideon Kasililika ${ }^{12^{*}}$ (D), Akin-Tunde Ademola Odukogbe ${ }^{2,3}$, Magbagbeola David Dairo ${ }^{2,4}$, \\ Belinda Stella Balandya ${ }^{5}$ and Emmanuel Kulwa Bunuma ${ }^{6}$
}

\begin{abstract}
Background: Female infertility is a public health problem, contributing to $65.9 \%$ of infertility in Tanzania. Lifestyle and oxidative stress (OS) have been suggested to affect female fertility; however, there are limited and controversial reports. This study aimed to determine the lifestyle and OS status of fertile and infertile women and relate lifestyle and OS to female infertility. The study was conducted among randomly selected 48 fertile and 48 infertile women aged 15-49 years attending a gynaecological clinic at Muhimbili National Hospital. Lifestyle information was collected using a proforma, and a sandwich ELISA method was used to analyse OS biomarkers (malondialdehyde and total antioxidant capacity). Chi-square, independent $t$ test and correlation coefficient were used for data analysis at $p<0.05$.
\end{abstract}

Results: Infertile women were significantly older (33.4 versus 30.3 years, $p=0.03$ ), got married at later ages (25.0 versus 22.8 years, $p=0.02)$, were in employment (62.5\% versus $29.2 \%, p=0.001)$, had attained university degree (56.3\% versus $27.1 \%, p=0.004)$ and were more obese, more likely to consume alcoholic drinks $(p=0.02)$ and less likely to use supplements $(p=0.000)$ than fertile women. Infertile women had statistically significant higher malondialdehyde $(p=0.000)$ and lower total antioxidant capacity levels $(p=0.000)$ than fertile women. The total antioxidant capacity level had a statistically significant negative correlation with alcohol consumption $(r=-0.27, p$ $=0.008)$ and obesity $(r=-0.32, p=0.002)$ and a positive correlation with supplement use $(r=0.24, p=0.02)$. Also, malondialdehyde level had a statistically significant positive correlation with alcohol consumption $(r=0.31, p=$ $0.002)$ and obesity $(r=0.28, p=0.007)$.

Conclusions: The differences in socio-demographic characteristics, lifestyle and oxidative stress between fertile and infertile women may account for difficulties in achieving pregnancy among infertile women in Tanzania. Lifestyle factors significantly affect oxidative stress. Health education on appropriate lifestyles that support female fertility and emphasis on supplement use during the preconception period may be beneficial in the management of female infertility.

Keywords: Female infertility, Lifestyle and oxidative stress status

\footnotetext{
* Correspondence: annarosemary04@gmail.com

'Department of Obstetrics and Gynaecology, Benjamin Mkapa Hospital,

Dodoma, Tanzania

${ }^{2}$ Pan African University Institute of Life and Earth Sciences-including Health

and Agriculture, University of Ibadan, Ibadan, Nigeria

Full list of author information is available at the end of the article
}

\section{Springer Open}

(c) The Author(s). 2021 Open Access This article is licensed under a Creative Commons Attribution 4.0 International License, which permits use, sharing, adaptation, distribution and reproduction in any medium or format, as long as you give appropriate credit to the original author(s) and the source, provide a link to the Creative Commons licence, and indicate if changes were made. The images or other third party material in this article are included in the article's Creative Commons licence, unless indicated otherwise in a credit line to the material. If material is not included in the article's Creative Commons licence and your intended use is not permitted by statutory regulation or exceeds the permitted use, you will need to obtain permission directly from the copyright holder. To view a copy of this licence, visit http://creativecommons.org/licenses/by/4.0/. 


\section{Background}

Infertility is a disease of the male or female reproductive system presenting with the inability to achieve clinical pregnancy following a period of 12 months or more of regular, unprotected sexual intercourse. Infertility is estimated to affect 48.5 million couples worldwide with a contribution of 10 million couples from Africa [1]. In developing countries like Tanzania, one in every four couples is affected by infertility [2]. Moreover, there has been a decrease in fertility rate in Tanzania from 6.2 children per woman in 1991-1992 to 5.2 in 2015-2016 with more burden on women in urban areas such as in Dar es Salaam, who are estimated to have a fertility rate of 3.8 children per woman [3].

The causes of infertility can arise from female only, male only or both partners, and in some cases, the cause is unexplained. The study in the Moshi region in Tanzania found that $65.9 \%$ of causes in the couples were from female infertility [4]. Female infertility is caused by pathologies within the female reproductive system such as ovulatory, tubal, uterine and peritoneal and cervical dysfunction [4-7].

Lifestyles include all modifiable characteristics and ways of life of an individual which have an impact on their well-being including reproductive capability [8]. These include age at the start of family, obesity, nutrition including supplement use such as folic acid, cigarette smoking, alcohol consumption and environmental and occupational exposure [9-11].

Oxidative stress (OS) occurs due to imbalance between reactive oxygen species (ROS) and antioxidants which may be due to increased ROS either endogenously generated during the mitochondrial respiratory chain process or from exogenous exposure such as tobacco smoke, alcohol and environmental chemical exposure. An imbalance may also arise when there is an inadequate amount of antioxidants to scavenge free radicals or inhibit excess ROS production [10,12, 13].

OS in female reproduction is suggested to affect follicle and oocyte maturation, ovarian steroidogenesis and embryo and placenta development [12-15]. The proposed mechanism is the effect of elevated ROS on cellular biomolecules (lipids, proteins and nucleic acids) and other cellular materials which lead to biomolecular damage such as lipid peroxidation of the cell membrane, deoxyribonucleic acid damage, inhibition of protein synthesis, depletion of adenosine tri-phosphate and cell apoptosis. The most frequently used methods with high sensitivity and high reproducible results in assessing biomolecular damage measure malondialdehyde (MDA) and total antioxidant capacity (T-AOC) [16].

Lifestyles and OS have been suggested to cause female infertility although there are limited and conflicting reports. The controversy is on the differences in lifestyles and OS status of fertile and infertile women and the relationship between lifestyles and OS status in female infertility. A study [17] found no significant difference in body mass index (BMI) in contrast to another study findings [18]. In addition, two studies [19, 20] found no significant differences in OS status while some studies [21-23] found significant differences between the two groups. Two studies [24, 25] conducted on male infertility found an impact of lifestyles (alcohol and tobacco use) on OS, but the effect on female infertility is unclear.

There are limited studies on lifestyles and OS among infertile women in Tanzania. Therefore, this study aimed at determining lifestyles and OS status of fertile and infertile women as well as identifying the relationship between lifestyles and OS in female infertility, which may provide baseline information for prevention and clinical management of infertility through emphasizing lifestyle modifications and supplement use among future fertility intending and infertile women.

\section{Methods \\ Study design and setting}

This comparative cross-sectional study was conducted from January 2019 to June 2019 at Gynaecology OutPatient Department (GOPD) and Central Pathology Laboratory, Muhimbili National Hospital (MNH), Dar es Salaam, Tanzania. MNH is the largest public hospital and is affordable for every socio-economic group of women within and outside Dar es Salaam. Dar es Salaam is the largest urban area in the country, located along the Indian Ocean coast.

The inclusion criteria in this study were women of reproductive age group (15-49 years), infertile women with either primary or secondary infertility and fertile women with a history of having had at least one childbirth, the latest within the last 2 years. Women with diabetes mellitus, cancer, blood clotting disorders, hypertension and other cardiovascular diseases were excluded from the study.

\section{Study description}

The minimum sample size was estimated using the statistical method for a comparative cross-sectional study, yielding a total of 48 participants for each of the two groups, after allowing for a $10 \%$ attrition rate [26]. The standard deviation of T-AOC level in infertile women $\left(\sigma_{1}\right)$ was $0.33 \mathrm{mmol} / \mathrm{L}$ and in fertile women $\left(\sigma_{2}\right)$ was 0.22 $\mathrm{mmol} / \mathrm{L}$, and the size of the mean difference of the two groups ("d") was $0.17 \mathrm{mmol} / \mathrm{L}$ as reported in the previous study [27].

The investigator and the trained research assistants (a nurse and a laboratory technician) approached the randomly sampled potential participant and requested for consent. Upon receiving written consent, the study 
Table 1 Socio-demographic characteristics of fertile and infertile women attending MNH, Dar es Salaam, Tanzania

\begin{tabular}{lll}
\hline Variables & $\begin{array}{l}\text { Fertile women } \boldsymbol{n = 4 8} \\
\text { Number (percentages) }\end{array}$ & $\begin{array}{l}\text { Infertile women } \boldsymbol{n}=\mathbf{4 8} \\
\text { Number (percentages) }\end{array}$ \\
\hline Age (years) & $30.3 \pm 6.5(20-47)$ & $33.4 \pm 6.8(22-48)$ \\
Age at marriage (years) ${ }^{a}$ & $22.8 \pm 4.8(12-34)$ & $25.0 \pm 4.2(15-38)$ \\
The highest educational level attained & & $21(43.7 \%)$ \\
$\quad$ Non-university degree & $35(72.9 \%)$ & $27(56.3 \%)$ \\
$\quad$ University degree & $13(27.1 \%)$ & $48(100.0 \%)$ \\
$\quad$ Total & $48(100.0 \%)$ & $18(37.5 \%)$ \\
The main work status & & $30(62.5 \%)$ \\
$\quad$ Un-employed & $34(70.8 \%)$ & $48(100.0 \%)$ \\
Employed & $14(29.2 \%)$ & \\
Total & $48(100.0 \%)$ & \\
\hline
\end{tabular}

${ }^{\mathrm{a}}$ Data are presented in mean \pm SD and minimum-maximum

participants were grouped into two. The first group included 48 infertile women and the second group had 48 fertile women. For each participant, an intervieweradministered proforma was filled.

The proforma contained 5 sections; the first section was on socio-demographic characteristics (age, age at marriage, the highest educational level attained, main work status) as well as gynaecological and obstetrics history (type, duration and causes of infertility, number of live births, menstrual regularity, menorrhagia, dysmenorrhea). The second and third sections were on lifestyles (alcoholic drink consumption and smoking in section two and supplement (folic acid) use in section three). The questions on lifestyles were modified from previous studies $[28,29]$. The fourth section was on anthropometric parameters which included height, weight and BMI as measured in another study [30] while the fifth section contained the laboratory results of MDA and TAOC concentrations.

After filling the interviewer-based questionnaire, a physical examination was done to measure anthropometric parameters, and lastly, an invitation to the laboratory for venous blood sample collection was done. Four millilitres of the venous blood sample was collected aseptically from participants by a qualified laboratory technician and was kept in a sterile tube labelled with participant's code initials and study number. The blood sample was then centrifuged on the same day at 3300 RPM for $10 \mathrm{~min}$, and serum obtained was kept in a labelled cryovial and stored at $-20^{\circ} \mathrm{C}$ for later analysis of oxidative stress biomarkers.

Before analysis, the serum samples were thawed to reach a temperature of $37^{\circ} \mathrm{C}$. Laboratory procedures in determining the concentrations of either MDA or TAOC in the samples followed the manufacturer's instructions (QayeeBio for Life Science Company, China) $[31,32]$. The method used was a double-antibody sandwich enzyme-linked immunosorbent one-step process assay (ELISA). It involved adding the standard, samples and horseradish peroxidase-labelled either MDA or T-AOC antibodies to enzyme wells which were pre-coated with either MDA or T-AOC antibody. It was then incubated and washed to remove the uncombined enzyme. Chromogen solutions A and B were then added. The colour of the liquid changed into blue, which later became yellow upon reaction with the added acid. The depth of the colour was positively correlated with the concentration of either MDA or T-AOC in the samples. The accuracy of MDA and T-AOC laboratory procedures was 0.997 and 0.9996 , respectively.

\section{Statistical analysis}

The socio-demographic characteristics (the highest level of education attained and the main work status) are summarized in frequencies and percentages while means

Table 2 Gynaecological findings of fertile and infertile women attending MNH, Dar es Salaam, Tanzania

\begin{tabular}{lllll}
\hline Variables & $\begin{array}{l}\text { Fertile women } \\
\boldsymbol{n}=\mathbf{4 8}\end{array}$ & $\begin{array}{l}\text { Infertile women } \\
\boldsymbol{n}=\mathbf{4 8}\end{array}$ & $\boldsymbol{X}^{\mathbf{2}}$ & $\boldsymbol{p}$ value \\
\hline Regularity of menstrual cycle & & $17(35.4 \%)$ & 19.5 & 0.000 \\
No & $1(2.1 \%)$ & $31(64.6 \%)$ & & \\
Yes & $47(97.9 \%)$ & $48(100.0 \%)$ & & \\
Total & $48(100.0 \%)$ & & & \\
Menorrhagia & & $29(60.4 \%)$ & 12.9 & 0.000 \\
No & $44(91.7 \%)$ & $19(39.6 \%)$ & & \\
Yes & $4(8.3 \%)$ & $48(100.0 \%)$ & & \\
Total & $48(100.0 \%)$ & & & \\
Dysmenorrhea & & & \\
No & $39(81.3 \%)$ & $24(50.0 \%)$ & 10.4 & 0.000 \\
Yes & $9(18.7 \%)$ & $24(50.0 \%)$ & & \\
Total & $48(100.0 \%)$ & $48(100.0 \%)$ & & \\
\hline
\end{tabular}


Table 3 Anthropometric and lifestyle findings of fertile and infertile women attending MNH, Dar es Salaam, Tanzania

\begin{tabular}{llll}
\hline Variables & Fertile women $\boldsymbol{n}=\mathbf{4 8}$ & Infertile women $\boldsymbol{n}=\mathbf{4 8}$ & $\boldsymbol{p}$-value \\
\hline BMI $\left(\mathrm{kg} / \mathrm{m}^{2}\right)^{\mathrm{a}}$ & $26.3 \pm 4.6(18.8-36.8)$ & $29.2 \pm 7.2(17.3-42.7)$ & 0.02 \\
Obesity & & & \\
$\quad$ Non-obese $<30 \mathrm{~kg} / \mathrm{m}^{2}$ & $37(77.1 \%)$ & $28(58.3 \%)$ & 0.05 \\
Obese $\geq 30 \mathrm{~kg} / \mathrm{m}^{2}$ & $11(22.9 \%)$ & $20(41.7 \%)$ & \\
Total & $48(100.0 \%)$ & $48(100.0 \%)$ & \\
\hline
\end{tabular}

${ }^{\mathrm{a}}$ Data are presented in mean $\pm \mathrm{SD}$ and minimum-maximum

and SDs were applied for age and age at marriage. The independent variables were socio-demographic characteristics and lifestyles (alcoholic drink consumption, obesity and supplement (folic acid) use). The dependent variables or research outcomes were oxidative stress biomarkers (MDA and T-AOC). Pearson's chi-square test $\left(X^{2}\right)$ was used to determine associations between lifestyles and female infertility.

Independent $t$ test $(t)$ was used to compare the mean differences of MDA and T-AOC in infertile and fertile women. Correlation coefficient $(r)$ was used to relate oxidative stress biomarkers (T-AOC and MDA) and lifestyles. Data analysis was done using the Statistical Package for Social Sciences (SPSS) version 20.0 and the level of statistical significance $(p)$ was taken as $<0.05$, two tailed. Double entry of data in the SPSS template was performed for verification.

\section{Results}

\section{Socio-demographic characteristics and gynaecological findings}

A total of 48 fertile women and 48 infertile women participated in this study. Infertile women were significantly older (33.4 years versus 30.3 years, $p=0.03$ ), got married at later years ( 25.0 years versus 22.8 years, $p=0.02$ ), had attained university degree $(56.3 \%$ versus $27.1 \%, p=$ $0.004)$ and were employed (62.5\% versus $29.2 \%, p=$ $0.001)$ compared to fertile women. It was also statistically significant that infertile women had more cases of irregular menstrual cycles, dysmenorrhea, and menorrhagia in comparison with fertile women. Fertile women with age below 35 years were more (79.5\% versus $56.2 \%)$ and $100 \%$ got married. Among infertile women, $70.8 \%$ had primary infertility and $45.8 \%$ had more than a 5year duration of infertility, and ovulatory and uterine causes contributed about $31.3 \%$ each in female infertility (Tables 1 and 2).

\section{Anthropometric measurements and lifestyle characteristics}

Infertile women had a significantly higher habit of consuming alcoholic drinks $\left(X^{2}=5.8, p=0.02\right)$, had higher BMIs $(t=-2.4, d f=94, p=0.02)$ and were non-users of supplements $\left(X^{2}=13.5, p=0.000\right)$ compared to fertile women. None of the women smoked (Table 3, Figs. 1 and 2).

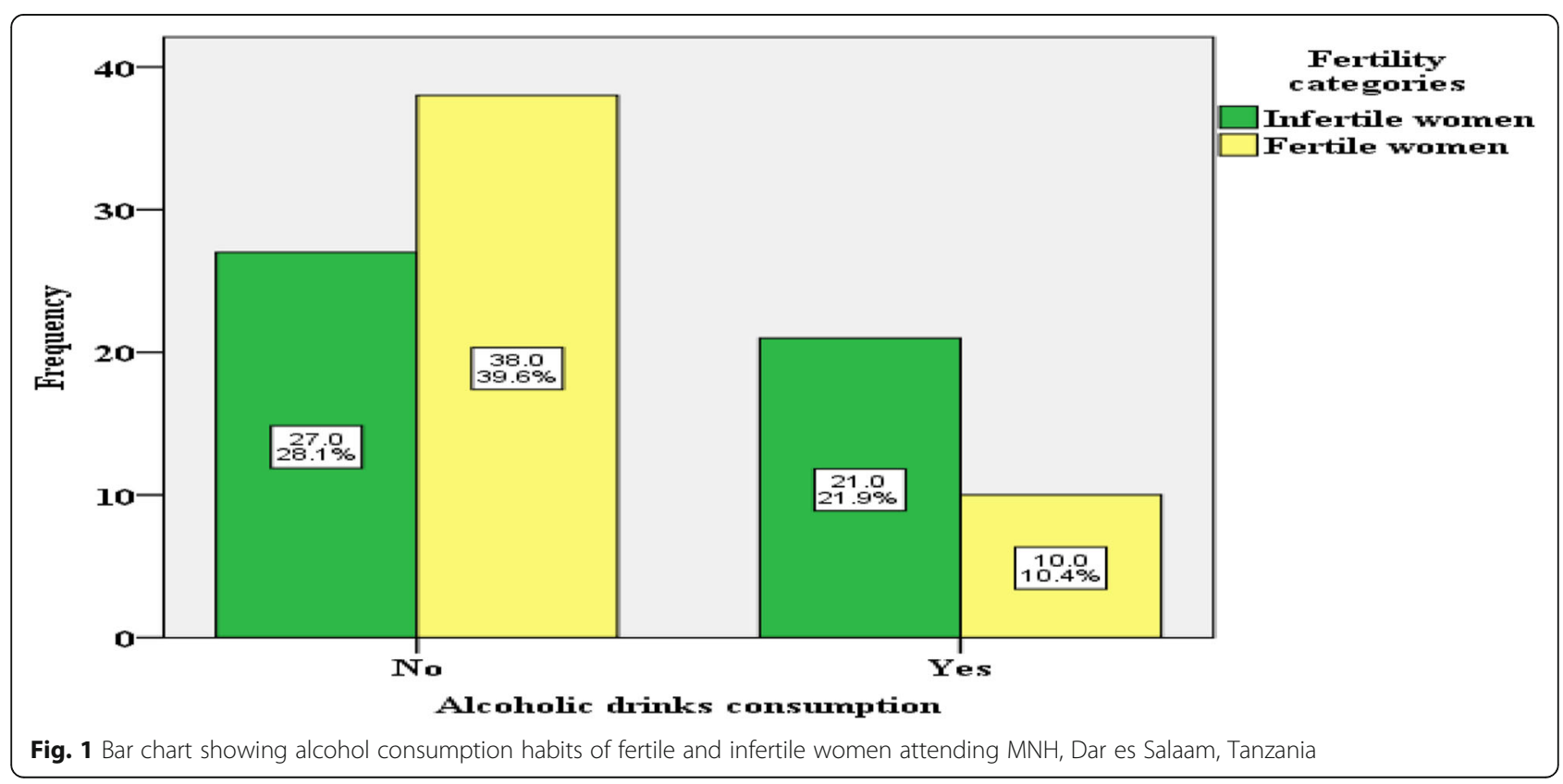




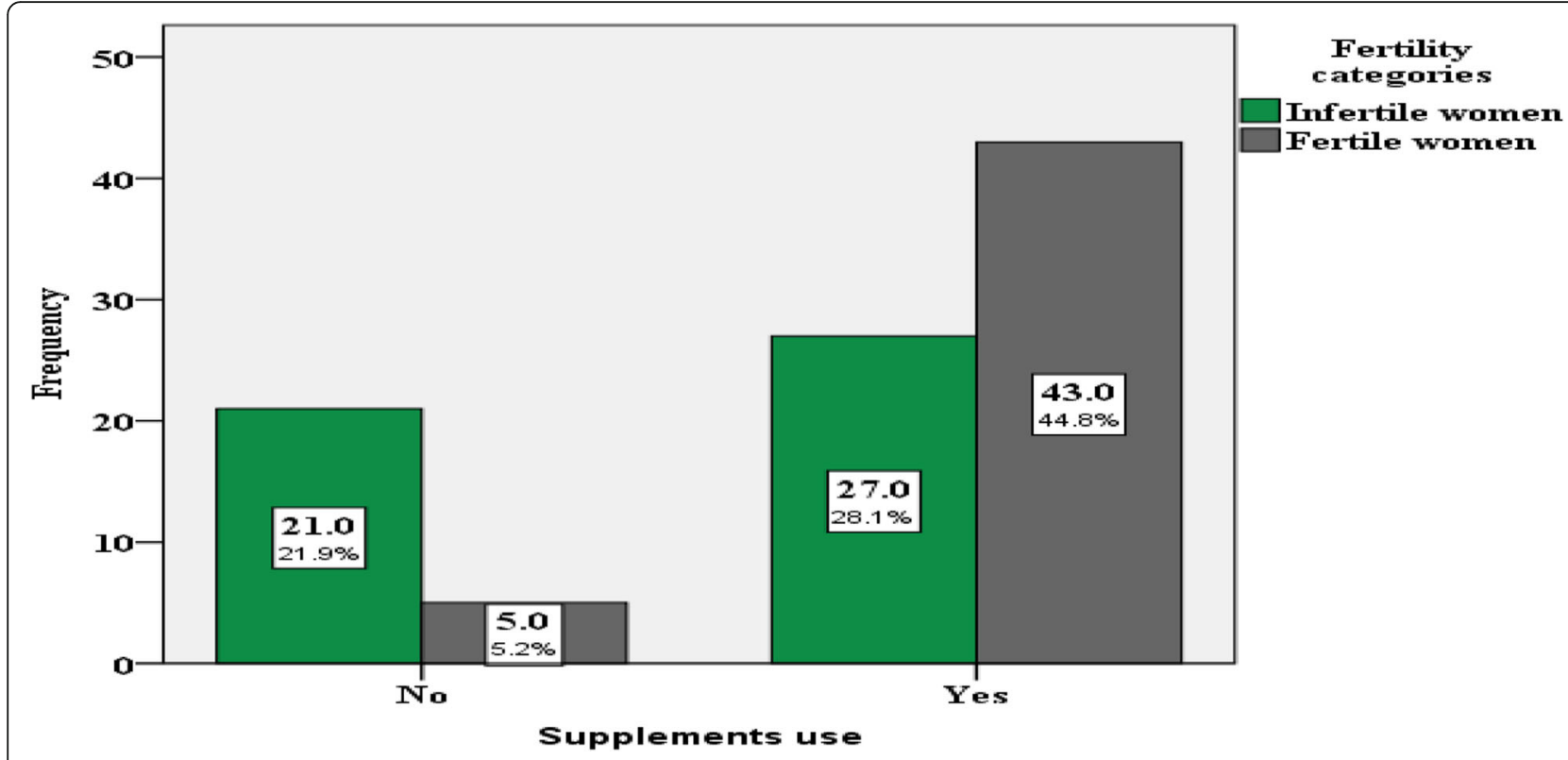

Fig. 2 Bar chart showing supplement use by fertile and infertile women attending MNH, Dar es Salaam, Tanzania

\section{OS status}

Infertile women had significantly higher MDA levels $(t=$ $-4.3, d f=94, p=0.000)$ and lower T-AOC levels $(t=$ 6.7, $d f=94, p=0.000$ ) than fertile women (Table 4).

\section{Relationship between lifestyle and OS}

T-AOC had a statistically significant negative correlation with alcohol consumption $(r=-0.27, p=0.008)$, obesity $(r=-0.32, p=0.002)$, age $(r=-0.20, p=0.05)$ and age at marriage $(r=-0.26, p=0.009)$. It also has a statistically significant positive correlation with supplement (folic acid) use ( $r=0.24, p=0.02)$, whereas MDA had a statistically significant positive correlation with alcohol consumption $(r=0.31, p=0.002)$, obesity $(r=0.28, p=$ $0.007)$, age $(r=0.3, p=0.003)$ and age at marriage $(r=$ $0.23, p=0.03$ ) and also a negative but not statistically significant with supplement (folic acid) $(r=-0.16, p=$ 0.11) (Table 5).

\section{Discussion}

This comparative cross-sectional study shows that there are significant differences between infertile and fertile women in terms of their socio-demographic characteristics, gynaecological findings and anthropometric, lifestyle choices and oxidative stress. Our study also reveals the relationship between lifestyles and oxidative stress.
Infertile women are significantly older and got married at later years than fertile women. Our findings are in line with previous studies $[9,11]$ that support female age being among important factors in determining her fertility. The mean age of infertile women is below 35 years which may suggest the possibility of early fertility decline probably due to premature ovarian failure or tubal blockage secondary to pelvic inflammatory diseases and may justify future research on possible risk factors for early fertility decline.

Our findings on the educational level of infertile women are contrary to what was found in another study [7]; however, this highlights the possibility of women delaying conception in order to achieve their career goals in similarity with another study [9]. It is well known that infertility management is costly [33]; being educated and employed, an infertile woman may be better able to afford the expenses of infertility care. However, this study did not determine the relationship between participants' level of education, their annual income and their health-seeking behaviour. This may warrant a further research in this area.

As a woman ages, so do the quantity and quality of her oocytes decline coupled with increased risks of gynaecological conditions like uterine fibroids and endometriosis which may explain the clinical presentations of menorrhagia,

Table 4 MDA and T-AOC values of fertile and infertile women attending MNH, Dar es Salaam, Tanzania

\begin{tabular}{llll}
\hline Variables & Fertile women $\boldsymbol{n}=\mathbf{4 8}$ & Infertile women $\boldsymbol{n}=\mathbf{4 8}$ & $\boldsymbol{p}$ value \\
\hline MDA level $(\mathrm{ng} / \mathrm{mL})$ & $43.3 \pm 27.4(10.2-106.6)$ & $67.2 \pm 26.7(9.9-116.8)$ & 0.000 \\
T-AOC level $(\mathrm{ng} / \mathrm{mL})$ & $133.4 \pm 31.8(49.3-177.4)$ & $89.8 \pm 31.5(23.4-187.6)$ & 0.000 \\
\hline
\end{tabular}

Data are presented in mean \pm SD and minimum-maximum 
Table 5 Correlation of oxidative stress biomarkers (MDA and T-AOC) with socio-demographic, anthropometric and lifestyle characteristics

\begin{tabular}{|c|c|c|c|c|}
\hline \multirow[t]{2}{*}{ Variables } & \multicolumn{2}{|l|}{ MDA } & \multicolumn{2}{|l|}{ T-AOC } \\
\hline & Correlation coefficient $(r)$ & $p$-value & Correlation coefficient $(r)$ & $p$-value \\
\hline \multicolumn{5}{|l|}{ Socio-demographic characteristics } \\
\hline Age & 0.30 & 0.003 & -0.20 & 0.05 \\
\hline Age at marriage & 0.23 & 0.03 & -0.26 & 0.009 \\
\hline \multicolumn{5}{|l|}{ Anthropometric measurements } \\
\hline Obesity & 0.28 & 0.007 & -0.32 & 0.002 \\
\hline \multicolumn{5}{|l|}{ Lifestyles } \\
\hline Alcoholic drink consumption & 0.31 & 0.002 & -0.27 & 0.008 \\
\hline Supplement (folic acid) use & -0.16 & 0.11 & 0.24 & 0.02 \\
\hline
\end{tabular}

dysmenorrhea and menstrual irregularity among infertile women. These gynaecological presentations were also reported among infertile women in the two previous studies $[4,6]$.

Another important finding of this study is that about half of infertile women are obese and consume alcoholic drinks. This is similar to other studies $[8,11,34]$. Among infertile women in one of them [11], 16\% were obese and $84 \%$ consumed alcoholic drinks. Our findings indicate there is a need for continuous health education on emphasizing the reduction of alcohol consumption and encouraging weight loss in our infertility patients. Although there is a tendency that alcoholic drinkers also smoke, none of the women in our study had a history of smoking. This is similar to the findings of another study [35].

Also, this study found that infertile women do not use folic acid supplements, contrary to other findings [34, 35]. The folic acid supplement use has been associated with increasing conception rate as well as better pregnancy outcome [36]. The majority of fertile women took folic acid supplements; this may be due to the existence of guidelines supporting the provision of folic acid supplement during antenatal and postnatal periods. It is thus important for the gynaecology clinic to promote and monitor folic acid supplement use among infertile women.

Our study indicates an increase in oxidative stress among infertile women. This is in line with the previous studies [7, 37] where higher MDA and lower TAC were reported in infertile women compared to fertile women. Oxidative stress occurs due to an imbalance between reactive oxygen species and antioxidant level. OS is associated with various diseases in the human body including infertility. In females, OS impairs oocyte maturation, embryo fragmentation and implantation and pregnancy progression [10]. Therefore, it may contribute to maternal and foetal morbidity and mortality if left unmanaged.

An important emerging result from this study is the correlation between lifestyle and OS, suggesting reducing OS effect on female fertility may be through lifestyle modifications as well as supplement intake. Our findings on lifestyle and OS are similar to those of some studies [21,36] but not in others [35]. A previous study [21] found a positive correlation between MDA and obesity $(r=0.34)$; however, this study was based on women with male infertility or unexplained causes. Obesity may lead to increased ROS, and when ROS is in an imbalanced state, it may result to OS [10].

The lifestyle information and oxidative stress biomarkers in this study were collected simultaneously; therefore, it may be difficult to establish the cause antedated effect. The participants were also required to give details on their lifestyles based on their ability to recall the events. Any suspicious response may lead to an incorrect relationship between lifestyles with oxidative stress. Therefore, findings from this study can be used to stimulate further research on the risk factors for oxidative stress status among infertile women.

\section{Conclusion}

This study demonstrates that older age, later age at marriage, higher BMIs, consumption of alcoholic drinks and non-use of supplements, also higher MDA and lower TAOC, are commoner in infertile than fertile women. These differences in socio-demographic characteristics, lifestyles and OS between fertile and infertile women may account for difficulties in achieving pregnancy among infertile women in Tanzania.

Our findings also strongly show that lifestyle (alcoholic drink consumption, obesity and inadequate supplement use) has correlations with MDA and T-AOC and their contribution to female infertility. Health education on appropriate lifestyles that support female fertility and emphasis on supplement use during the preconception period may be beneficial in the management of female infertility.

\section{Abbreviations}

ROS: Reactive oxygen species; MDA: Malondialdehyde; OS: Oxidative stress; TAOC: Total antioxidant capacity 


\section{Acknowledgements}

We thank Dr. Magere Mguri and Mrs. Christina Tairo for their assistance during data collection.

\section{Authors' contributions}

AGK conceived and designed the study, recruited and collected the data, analysed and interpreted the data, drafted the manuscript and wrote the final version. $A A O$ assisted in designing, analysis, interpreting and drafting of the manuscript; BSB assisted in the study coordination and manuscript drafting; MDD assisted in the data analysis, interpretation and drafting of the manuscript; EKB assisted in designing, laboratory work and data analysis. All authors read and approved the final manuscript.

\section{Funding}

This study was funded by an MSc research grant from Pan African UniversityAfrican Union Commission. The funder has no role in the design of the study, data collection, analysis and interpretation of the data and writing the manuscript.

\section{Availability of data and materials}

The datasets used and/or analysed during the current study are available from the corresponding author on reasonable request.

\section{Declarations}

\section{Ethics approval and consent to participate}

An informed written consent was obtained from participants prior to data collection. Ethical clearance was obtained from the University of Ibadan/ University College Hospital, Ibadan Ethics Committee (reference number UI/ EC/18/0649) and Muhimbili National Hospital (MNH) Ethical Review Board (reference number MNH//RB/1/2019/195).

\section{Consent for publication}

Informed consent for publication was taken from participants before data collection.

\section{Competing interests}

The authors declare that they have no competing interests.

\section{Author details}

'Department of Obstetrics and Gynaecology, Benjamin Mkapa Hospital, Dodoma, Tanzania. ${ }^{2}$ Pan African University Institute of Life and Earth Sciences-including Health and Agriculture, University of Ibadan, Ibadan, Nigeria. ${ }^{3}$ Department of Obstetrics and Gynaecology, Faculty of Clinical Sciences, College of Medicine, University of Ibadan/University College Hospital, Ibadan, Nigeria. ${ }^{4}$ Department of Epidemiology and Medical Statistics, Faculty of Public Health, College of Medicine, University of Ibadan/ University College Hospital, Ibadan, Nigeria. ${ }^{5}$ Department of Obstetrics and Gynaecology, School of Medicine, Muhimbili University of Health and Allied Sciences/Muhimbili National Hospital, Dar es Salaam, Tanzania. ${ }^{6}$ Tanzania Veterinary Laboratory Agency, Kibaha, Coast, Tanzania.

\section{Received: 26 February 2021 Accepted: 2 September 2021}

\section{Published online: 21 September 2021}

\section{References}

1. Mascarenhas MN, Flaxman SR, Boerma T, Vanderpoel S, Stevens GA (2012) National, regional, and global trends in infertility prevalence since 1990: a systematic analysis of 277 health surveys. PLoS Med 9(12):12. https://doi. org/10.1371/journal.pmed.1001356

2. Rutstein SO, Iqbal HS (2004) Infecundity, infertility and childlessness in developing countries DHS comparative reports No.9. ORC Macro and the World Health Organization, Calverton

3. Ministry of Health, Community Development, Gender, Elderly and Children MoHCDGEC/Tanzania Mainland, Ministry of Health - MoH/Zanzibar, National Bureau of Statistics - NBS/Tanzania, Office of Chief Government Statistician OCGS/Zanzibar, and ICF. 2016. Tanzania Demographic and Health Survey and Malaria Indicator Survey (TDHS-MIS) 2015-16. Dar es Salaam/Tanzania: MoHCDGEC, MoH, NBS, OCGS, and ICF
4. Larsen U, Masenga G, Mlay J (2006) Infertility in a community and clinic based sample of couples in Moshi, Northern Tanzania. East Afr Med J 83(1): 10-17

5. Osman AA (2010) Aetiology of female infertility in Gezira (Central of Sudan). J Appl Sci 10(19):2333-2337. https://doi.org/10.3923/jas.2010.2333.2337

6. Hussain MK, Mohammed HJ, Al-Ghazali BS, Hasan TA (2013) Oxidative stress in primary infertility of women. Glob J Med Res Orthop Muscular system 13: 2

7. Panti AA, Umar AB, Rabiu UA, Saidu Y, Bilbis LS, Shehu CE et al (2018) Evaluation of oxidative stress, gonadotrophins and prolactin in infertile women. Eur J Pharm Med Res 5(3):505-511

8. Khosrorad T, Dolatian M, Riazi H, Mahmoodi Z, Alavimajd H, Shahsavan S et al (2015) Comparison of lifestyle in fertile and infertile couples in Kermanshan during 2013. Iran J Reprod Med 13(9):549-556

9. George K, Kamath M (2010) Fertility and age. J Hum Reprod Sci 3(3):121123. https://doi.org/10.4103/0974-1208.74152

10. Agarwal A, Mellado AA, Premkumar BJ, Shaman A, Gupta S (2012) The effects of oxidative stress on female reproduction: a review. Reprod Biol Endocrinol 10(1):49. https://doi.org/10.1186/1477-7827-10-49

11. Piché M-LP, Babineau V, Robitaille J, Lachance É, Ruchat SM (2018) Lifestylerelated factors associated with reproductive health in couples seeking fertility treatments: results of a pilot study. Int J Fertil Steril 12(1):19-26. https://doi.org/10.22074/ijfs.2018.5135

12. Sinha A, Gupta S (2018) Lipid peroxidation and its impact on infertility. Women Health Gynecol 4:1

13. Lu J, Wang Z, Cao J, Chen Y, Dong Y (2018) A novel and compact review on the role of oxidative stress in female reproduction. Reprod Biol Endocrinol 16(1):80. https://doi.org/10.1186/s12958-018-0391-5

14. Gupta S, Malhotra N, Sharma D, Chandra A, Agarwal A (2009) Oxidative stress and its role in female infertility and assisted reproduction: clinical implications. Int J Fertil Steril 2(4):147-164

15. Adedapo KS, Olayemi O, Odukgobe AA, Aimakhu CO, Kehindi AO, Salako BI (2011) Increased oxidative stress in Nigerian women with pre-eclampsia. SAJOG 17:2

16. Marrocco I, Altieri F, Peluso I (2017) Measurement and clinical significance of biomarkers of oxidative stress in humans. Oxidative Med Cell Longevity.

17. Jargar JG, Dhundasi SA, Punekar MD (2017) Status of alpha tocopherol concentration and oxidative stress in infertile females of Vijayapur District, Northern Karnataka. National Journal of Physiology, Pharmacy and Pharmacology.

18. Youness EM (2018) Lifestyle factors between fertile and infertile women at Assiut Women's Health Hospital. Egypt Nurs J 15(1):9-20

19. Nsonwu-Anyanwu AC, Charles-Davies MA, Oni AA, Taiwo VO, Bello FA (2011) Chlamydial infection, plasma peroxidation and obesity in tubal infertility. Ann Ibd Pg Med 9(2):83-88

20. Nasiri N, Moini A, Eftekhari-Yazdi P, Karimian L, Salman-Yazdi R, Zolfaghari Z, Arabipoor A (2015) Abdominal obesity can induce both systemic and follicular fluid oxidative stress independent from polycystic ovary syndrome. Eur J Obstet Gynecol Reprod Biol 184:112-116. https://doi.org/10.1016/j. ejogrb.2014.11.008

21. Shaeer EK, El-Ghareeb AA (2014) Obesity and follicular fluid oxidative stress: relationship to ICSI outcome. Middle East Fertil Soc J 19(2):139-143. https:// doi.org/10.1016/j.mefs.2013.07.002

22. Nsonwu-Anyanwu AC, Charles-Davies MA, Taiwo VO, Oni AA, Bello FA, Li B (2015) Female reproductive hormones and biomarkers of oxidative stress in genital Chlamydia infection in tubal factor infertility. J Reprod Infertil 16(2):82-89

23. Rad SS, Abbasalizadeh S, Haghjo AG, Sadagheyani S, Montaseri A, Rad IS (2015) Evaluation of the melatonin and oxidative stress markers level in serum of fertile and infertile women. Iran J Reprod Med 13(7):439-444

24. Khalil AA, Hussein HM, Sarhan EM (2012) Oxidative stress induces idiopathic infertility in Egyptian males. Afr J Biotechnol 11(6):1516-1522

25. Aboulmaouahib S, Madkour A, Kaarouch I, Sefrioui O, Saadani B, Copin H, Benkhalifa M, Louanjli N, Cadi R (2018) Impact of alcohol and cigarette smoking consumption in male fertility potential: looks at lipid peroxidation, enzymatic antioxidant activities and sperm DNA damage. Andrologia 50(3): 3. https://doi.org/10.1111/and.12926

26. Rosner B (2000) Fundamentals of biostatistics, Cengage Learning, 5th edn

27. Isong IK, Eze-Bassey I, Okpokam DC, Okhormhe ZA, Usoro CAO, Udoh AE (2016) The effect of prolactin, total antioxidant capacity, antisperm antibodies and the presence of chlamydia trachomatis lgG in fertile and infertile women in Calabar, Nigeria. IOSR J Dent Med Sci 15(3):63-68 
28. WHO STEPS Instrument (core and expanded) (2008) The WHO STEPwise approach to chronic disease risk factor surveillance. World Health Organization, Geneva

29. TFNC (2014) Tanzania national nutritional survey, Dar es Salaam, Tanzania.

30. Heymsfield SB, Baumgartner RN, Pan S (1999) Nutritional assessment of malnutrition by anthropometric methods. In: Modern nutrition in health and disease, 9th edn. Lippincott Williams\&Wilkins, Philadephia

31. QayeeBio (2019) QY-E00059 human total antioxidant capacity (T-AOC) ELISA kit. http://www.qayeebio.com . Accessed 23 Aug 2019.

32. QayeeBio (2019) QY-E04112 human malondialdehyde (MDA) ELISA kit. http://www.qayeebio.com. Accessed 23 Aug 2019.

33. Nieuwenhuis SL, Odukogbe A-TA, Theobald S, Liu X (2009) The impact of infertility on infertile men and women in Ibadan, Oyo State, Nigeria: a qualitative study. Afr J Reprod Health 13(3):85-98

34. Gormack AA, Peek JC, Derraik JG, Gluckman PD, Young NL, Outfield WS (2015) Many women undergo fertility treatment make poor lifestyle choices that may affect treatment outcome. Hum Reprod 30(7):1617-1624. https:// doi.org/10.1093/humrep/dev094

35. Ruder EH, Hartman TJ, Reindollar RH, Goldman MB (2014) Female dietary antioxidant intake and time to pregnancy among couples treated for unexplained infertility. Fertil Steril 101(3):759-766. https://doi.org/10.1016/j. fertnstert.2013.11.008

36. Panti AA, Shehu CE, Saidu Y, Tunau KA, Nwobodo El, Jimoh A et al (2018) Oxidative stress and antioxidants supplementation in patients with PCOS. Int J Reprod Gynaecol 7(5):1667-1672

37. Rajeshwary P, Nagaprasanth M, Salma Mahaboob R, Obulesu G (2016) Evaluation of oxidative stress markers in infertile women. Int Arch Integr Med 3(10):239-244

\section{Publisher's Note}

Springer Nature remains neutral with regard to jurisdictional claims in published maps and institutional affiliations.

\section{Submit your manuscript to a SpringerOpen ${ }^{\circ}$ journal and benefit from:}

- Convenient online submission

- Rigorous peer review

- Open access: articles freely available online

- High visibility within the field

- Retaining the copyright to your article

Submit your next manuscript at $\boldsymbol{\nabla}$ springeropen.com 